\title{
Knowledge Maps in Open Learning Environments: An Evaluation from Learners' Perspectives
}

\author{
Heba Fasihuddin ${ }^{* 1}$, Geoff Skinner ${ }^{2}$, Rukshan Athauda ${ }^{3}$ \\ Faculty of Science and Information Technology, The University of Newcastle, Callaghan, Australia \\ ${ }^{*}$ Heba.Fasihuddin@uon.edu.au; ${ }^{2}$ Geoff.Skinner@newcastle.edu.au; ${ }^{3}$ Rukshan.Athauda@newcastle.edu.au
}

\begin{abstract}
This paper presents a study that looks at ways to support learners in open learning environments by applying cognitive science and learning theories. Open learning is a form of online learning that allows learning materials and courses to be freely available on the Internet and accessible to anyone who is interested. The focus in this paper is the presentation of learning contents. Based on the concept of schema theory, the knowledge map has been chosen to organise and present learning contents. The aim is to support learners for self-regulated learning by providing a full encapsulation for course contents to help them, especially novice learners, to conceptualise the domain and the structure of the course. A prototype has been developed and piloted on a group of IT students. The students' perspectives on the use of the knowledge maps and how they affect their learning have been collected through two surveys. A total of 49 surveys have been collected and reported in this paper. The result is promising and an indication of the likely success of such an approach.
\end{abstract}

\section{Keywords}

Kknowledge Maps; Learning theories; MOOCs; Open Learning

\section{Introduction}

Computing technologies revolutionises the way people access and share information. Due to recent technology advancements such as cloud computing and ubiquitous networks, online learning has embraced a new form called open learning which allows learning materials to be freely available on the Internet for any interested learners. To add to this phenomenon, universities, who traditionally have been the guardians of advanced knowledge and creating new knowledge through research, are joining in the foray of online learning opening up their courses to the world with Massive Open Online Courses (MOOCs)(Breslow et al. 2013) which aim to place education freely available for any learner. This is truly a revolutionising phenomenon.

The emergence of open learning raises the need to revisit learning and teaching practices to take advantage of opportunities in these learning environments. The traditional classrooms where teachers expound knowledge and students interact with the teachers are not the only mean for information dissemination in open learning environments. Rather learners are given more freedom and flexibility to search and gain plethora of information (usually in different forms - video, audio, simulations, etc.) whereby the learner can independently interact and learn at their own pace. In addition, these learning environments target a massive number of learners with different cognitive capabilities, prior knowledge and preferences. This makes the authors believe that there is lots of potential for research and development to facilitate better learning experience catering to learner's needs, preferences and cognitive abilities.

Education researches over the past decades have enhanced our understanding of how humans learn and given us theories, models and concepts in learning. The authors believe that applying these learning principles with the use of contemporary technological advancements will enable a richer learning experience. This view is supported by other researchers (Williams 2013).

This paper presents an experiment where a schema theory (Bartlett 1932) has been considered in organising learning materials as a way to support learners in conceptualising learning concepts. Knowledge maps (Ifenthaler and Hanewald 2014) were used as a mean to apply the theory and organise learning materials in an open 
environment where learners traverse these materials and learn them independently at their own pace. In addition, the paper also presents learners' evaluation of using this approach. This evaluation has been conducted by eliciting learners' views through 5 point Likert scale surveys and analysing the results. This paper is organised as follows: section 2 presents background and related work with regards to Schema Theory, Knowledge Maps and current work using knowledge maps. Section 3 discusses the research questions and design of the experiment and methodology. Section 4 presents results and findings. Finally, the limitations of the study and conclusions are provided in sections 5 and 6 respectively.

\section{Background}

The evolution of technology leads to continual changing and development in learning approaches and open learning is a novel emerged form of online learning. In open learning, resources are freely available on the Internet to be accessed by anyone who is interested. These resources are provided by different learning providers who could be academics representing learning institutions or individuals who have appropriate knowledge and expertise. In the context of the presented study, the authors define open learning as a form of distance education where learning materials are delivered online over the Internet and can be accessed and learnt by anyone without any restriction. Open learning is a self-regulated learning where learners are in the role of organising and learning at their own pace and this mainly distinguishes it from other learning approaches where courses are guided by instructors or learners who are able to synchronously interact with instructors and other learners.

Recently, many academics have changed their practice by publishing their learning materials online and thus allowing their expertise to be accessed in an open form. This practice has gradually refined into what is known as Massive Open Online Courses (MOOCs). These courses offer free university-level courses online and have two key features - open access and scalability (Yuan and Powell 2013). These two features allow MOOCs to be taken online by anyone and enable them to be designed to support an indefinite or even infinite number of participants. MOOCs were originally constructed in 2008 by Stephen Downes and George Siemens who created the online course Connectivism and Connective Knowledge (Parr 2013). After that, a number of similar initiatives were established. Some of these initiatives are run by prestigious educational institutions, such as Stanford, Harvard, and MIT, while others are by private organisations and individuals. These initiatives include Coursera (Coursera 2012), edX (edX 2012), Udacity (Udacity 2012), Udemy (Udemy 2014) and others. All of these initiatives provide learning in an open, flexible form that allows anyone to take them up and learn. However, every learning provider has its own goals for initiating such a service and its own approaches to providing learning materials (Fasihuddin, Skinner, and Athauda 2012).

While the self-regulation in open learning offers a great opportunity of freedom in organising, selecting and learning, many learners also face the issue of cognitive overload as well as conceptual and navigational disorientation (Wang et al. 2011). Cognitive over load refers to the situation whereby learners have to process too much information than what their short memories are able to handle. Many learners are unable to process different kinds of information and become easily hampered by limited working memory (Wang et al. 2011). The possibility of this challenge is even greater with advanced topics that consist of more complex knowledge structure and with novice learners who lack any sufficient knowledge in the domain of the provided learning materials. The authors believe that organising the learning content in open learning environments plays an essential role in supporting and facilitating the learning process. Therefore, this study aims to address this concern by applying learning theories and techniques such as knowledge maps in contemporary online learning environments.

Based on cognitive theories, one of the reasons for online learners to face lack of information retention is the inability to form a mental picture or vision of the presented information (Chalmers 2003). According to Sweller (Sweller 1994), schemas which is the cognitive construct that organises the element of information based on human understanding, is the primary mechanism of information acquisition and learning. The authors believe that conceptualising the learning concepts in schemas is a key for learners to visualise the learning contents and start acquiring the presented information. Therefore, in this study, organising the learning materials in open learning environments follows the schema theory principals and knowledge map representation. The following section provides an overview of schema theory, knowledge maps and how schema theory principals are applied using knowledge maps. 


\section{Applying Schema Theory through Knowledge Maps}

Schemas are generally thought of as ways of incorporating instructions into our cognition. Schema theory is a cognitive learning theory that was first introduced by Bartlett (Bartlett 1932). This theory states that all knowledge is organised into units, and within these units information is stored. Schema theory has been also described as the basic building blocks of knowledge and intellectual development that store concepts in human memory (Satzinger 1998). According to Sweller (Sweller 1994), knowledge and related intellectual skills are heavily dependent on schema acquisition. In addition, Chalmers stated that organising schema is especially important for novice learners and essential for low ability learners (Chalmers 2003). He also noted that, to form a schema, learners need to understand where the newly presented concept fits into the big picture. Thus the authors hypothesise that learning concepts need to be presented in such a way that ensures the building of that schema in learners' memories and which consequently will assist in the learning process. Expert generated knowledge maps, which are designed by an expert in the field, such as a lecturer, to visually present knowledge, has the ability to organise and present learning concepts and materials in an intuitive manner for the learner.

Knowledge maps are a visual representation of knowledge that use different graphical shapes (Li-Yu, Yu-Shih, and Chih-Ping 2012). They have been also defined as graphical display of information in which the importance and relationships between the various elements of knowledge are portrayed in the form of a map (Ifenthaler and Hanewald 2014). Knowledge maps represent an overview of specific knowledge by breaking the knowledge down into concepts that are related to each other. Concepts in knowledge maps are represented by ovals and the relationships between these concepts are represented by lines or arrows. These lines can be labelled or not (Coffey 2005).

Knowledge maps can be constructed in different forms, such as chain (also known as sequential) maps, cyclical maps and hierarchical map (Ifenthaler and Hanewald 2014). Chain maps are used to indicate a sequence of events or process. Cyclical maps are used to show how various concepts are connected and linked together in a closed loop. Hierarchical maps are used to show the relation of concepts in a hierarchal structure with the most general concepts at the top of the hierarchy and the less general coming hierarchically lower. A study has found that hierarchal knowledge maps are more helpful than other forms for learners with low prior knowledge, as learners found to gain more conceptual knowledge and had to invest less mental effort in tests after learning with hierarchal maps (Amadieu et al. 2009). It has been stated that hierarchal maps are the most appropriate form to represent static knowledge ( $\mathrm{Ng}$ and Hanewald 2010), and as such it has been selected in this study to organise the learning materials. A simple illustration of a hierarchal knowledge map is presented in Fig. 1.

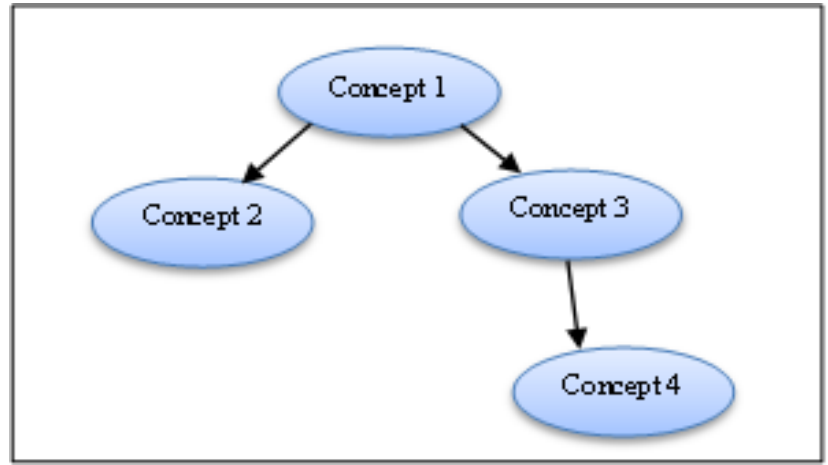

FIG. 1 SIMPLE ILLUSTRATION OF THE MAIN COMPONENTS OF KNOWLEDGE MAPS

Knowledge maps were found to be effective and supportive in traditional learning processes. Hall, Dansereau, and Skaggs (Hall, Dansereau, and Skaggs 1992) found that students who used knowledge maps were able to recall more critical and central concepts than students who used texts. In addition, it was found that students with low verbal abilities or base knowledge benefited the most from the conceptualisation of knowledge maps (Rewey et al. 1989). Moreover, from a psychological perspective, the knowledge map was found to decrease students' anxiety regarding learning materials and to increase their motivation (Hall and O'Donnell 1996). In addition, it has been found that the use of knowledge maps improves students' performance and in the physical science laboratories (Safdar et al. 2013). All of these findings are consistent with schema theory and have inspired the authors to 
hypothesize that knowledge maps will be equally effective in open learning environments and will provide the required support for learners.

Although the benefits of knowledge maps are numerous, there are some reported limitations that might affect their effectiveness in learning. Map shock, cognitive overload, and lack of personalisation are reported as the main limitations of knowledge maps. It is stated that large scale knowledge maps, such as maps conceptualising a whole course, lack the simplicity of conceptualisation that knowledge maps should provide, and consequently learners may encounter map shock. When the number of conceptual nodes increases, the map becomes too complex for the learner to cognitively process, leading to confusion and that what is described here as map shock (Advancing Personalized Learning Via an Adaptive Concept Map)(Advancing Personalized Learning Via an Adaptive Concept Map)(Advancing Personalized Learning Via an Adaptive Concept Map)(Advancing Personalized Learning Via an Adaptive Concept Map, nd). Therefore, applying knowledge maps to learning environments should work within the mentioned limitation so that the greatest potential benefit can be achieved.

In this study, to address the limitation of map shock while still incorporating knowledge maps to organise and conceptualise concepts, courses contents were broken down into several main topics, so that the knowledge map can be created to visualise the concepts of each topic instead of a whole course. This will help learners to visualise the schema of each topic and its related concepts and consequently lead to better information retention.

\section{Related Work}

In literature, there are some studies that have implemented knowledge maps as an approach to teach, organise and deliver learning contents. However, the previous studies of knowledge maps were concerned more with the effect of knowledge maps on traditional and blended learning, not on self-regulated open learning environments. One study that compared the design of browser-based learning materials and knowledge map-based materials found that knowledge map-based designs can promote online learning performance (Shaw 2010). Another study has suggested that knowledge maps can be used for curriculum planning and design. This study claimed that this could enhance teaching and learning as knowledge maps highlight the key learning concepts to be taught and their relationships (Novak and Cañas 2006). This approach has been already applied on the Cmappers website to learn about concept mapping (Cmappers.Learn, 2013). It was developed using CmapTools software (IHMC). In addition, NASA Amex has used this to develop a rich learning environment, a website full of different learning resources to learn about Mars (Briggs et al. 2004). These learning resources have been organised in a concept map format using the CmapTools software (IHMC). Another study that was presented by (MacKinnon et al. 2014) investigated the use of concept mapping in curriculum planning and design on four different subjects. This study found that organising the course contents into concept maps positively impacted the teaching process. This is because the instructors are able to recall linkages and relationships between different concepts by looking at the constructed concept maps. In addition, the same study has reported that students at the later stage of courses found that concept mapping allowed them to remember what concepts they had studied at the beginning of a course and the linkages between different concepts (MacKinnon et al. 2014).

As mentioned earlier, the previous studies applied knowledge maps on traditional and blended learning environments, and, to the authors' knowledge, no previous studies or evaluations have been held solely in an open learning environment where learners learn independently of teacher's interaction in a self-regulated way. Based on that and the previously presented benefits of knowledge maps, as well as the consideration of the concept of schema theory, we proposed to evaluate the adoption of knowledge maps to organise learning materials in an open learning environment. The proposed study aims to evaluate the learners' satisfaction about using knowledge maps to organise learning concepts and whether they find this approach supportive to their learning process. This evaluation is based on students' perspectives and perceptions after experiencing learning organised with knowledge maps.

\section{Research Design}

The research methodology for this study has been selected to fulfil the aim of the study, which is evaluating the impact of using knowledge maps on supporting self-regulated learning process in open learning environments. In 
particular, the study aims to answer the following questions:

1) Do students agree that the use of knowledge maps support their learning process by conceptualising the learning concepts?

2) Do students agree that organising learning materials into concepts in knowledge maps support them to learn independently?

Due to the nature of this research a mix of quantitative, qualitative and engineering research methods have been selected to achieve the desired aim. First of all, we proposed to construct a prototype that simulates open learning environments while also incorporating knowledge maps to organise the learning concepts. This constructed prototype needed to be piloted and evaluated by real learners in order to get their feedback and perspectives about the usage of knowledge maps and whether it supported them in learning independently. Therefore it was proposed to conduct a pilot study on a course at the university and then ask the learners who participated in the study to provide their perspectives about their learning experience through surveys that involve some quantitative and qualitative questions. These questions were designed and chosen in alignment with the Technology Acceptance Model (TAM) (Davis 1989), which is widely applied and utilised in Information Systems research. It was selected to be applied in this study as it fulfils the desired aim by answering the posed research questions. TAM suggests that users' acceptance of a new technology is influenced by two factors: (a) perceived usefulness, and (b) perceived ease-of-use. The questions of both surveys were developed around these two factors so that required data can be collected for evaluation of our prototype.

The prototype for this study was developed as a website known as CALC. This website simulates open learning environments by providing free online learning materials that learners can access to learn independently at their own pace. In addition, this website is able to host many courses and the learning contents for these courses can be organised with knowledge maps.

The development of knowledge maps has been grounded on computer-based knowledge maps. In a computerbased knowledge map every node representing a learning concept should link to a set of different, related learning resources by clicking an associated icon or hyperlink to that node. There are several tools to create digital knowledge maps, such as CmapTool (IHMC), Knowledge Master (KnowledgeMaster 2011) and Inspiration (Inspiration 2014). None of these tools were used to develop the knowledge maps in this study. This is because this study aims to foster the functionality of knowledge maps and how they support self-regulated learning by adding assessment items along with the other learning resources to each node of the knowledge map so that every learner has the ability to assess their learning progress and track that on the knowledge map. The progress is reflected on the knowledge maps by colours, so successfully learnt and completed concepts/nodes are distinguished with a different colour to the other nodes. We believe this will provide more support to the self-regulated learner.

\section{Prototype Design and Development}

The CALC prototype has been developed as a website using ASP.net technology. The website has two main phases. The first phase is for instructors where they can create courses, knowledge maps and add learning resources. The construction of knowledge maps in the prototype is done by inserting the course data manually as generating automatic knowledge maps is not within the scope of this study. Instructors insert the concept names along with their dependencies to construct the knowledge maps. In order to reduce map shock, it was decided to break courses into topics and create knowledge maps for the topics instead of the entire course. So, first, instructors create a course and its main topics. Then the knowledge map can be constructed for each topic by inserting the concept names. After creating the knowledge maps, the learning resources and assessment items can be created for each concept. Learning resources are collected from different online sources and added to each concept so every concept has a list of hyperlinks to related learning materials. In regards to the assessment items, instructors are able to create multiple choice questions for each concept, so that every concept will have a set of questions which together form a test bank.

The second phase is for the learners where they are able to access the various provided courses and learning resources. First, a learner needs to select a course and the desired topic under this course. After this selection the learner will view learning concepts organised in a knowledge map. Screen shots of the knowledge map and 
learning materials of a concept are shown in Fig. 2. Every oval in the knowledge map represents a learning concept that can be clicked to access a list of hyperlinks that will guide the learner to a variety of learning resources for that particular concept. In addition, while the learner is on the concept page, he/she has the option to take a test to evaluate his/her learning progress, which the learner needs to be logged in to be able to take. After taking the test, the learner receives their result with a report that shows the state of each question with the option to show the right answer in cases where the answer was wrong. The concept is considered successfully completed if the test result is $50 \%$ or more and consequently its colour is changed in the knowledge map from blue to green. Screen shots of the test, report and the updated knowledge map are shown in Fig. 3.



FIG. 2 SCREEN SHOTS OF A CALC KNOWLEDGE MAP AND CONCEPT LEARNING MATERIALS

\section{Knowledge Map Construction}

It is believed that expert knowledge maps reduce mis-conceptualisation and provide a solid foundation to start the course more effectively (Wang et al. 2011). Therefore, the knowledge maps in this study were all created and reviewed by lecturers who have expertise in the field.

Constructing the knowledge maps in this study has been conducted based on the process that was provided by (Moore, Pierce, and Williams 2012) along with some additions by the authors. The applied process is as follows:

1) Lecturers start creating the knowledge maps by dividing the course into main topics in order to simplify the knowledge maps and reduce map shock.

2) Use textbooks and course syllabi to brainstorm the main concepts to be taught under each topic and record them as notes.

3) Group concepts that are usually taught together and label these groups.

4) Check for repeated concepts in groups and delete them.

5) In each group, organise concepts and link them based on their relationships to form small knowledge maps of each group.

6) Link the small knowledge maps together in order to form one topic knowledge map.

7) Revise and refine the resultant knowledge map by discussing with other lecturers. 


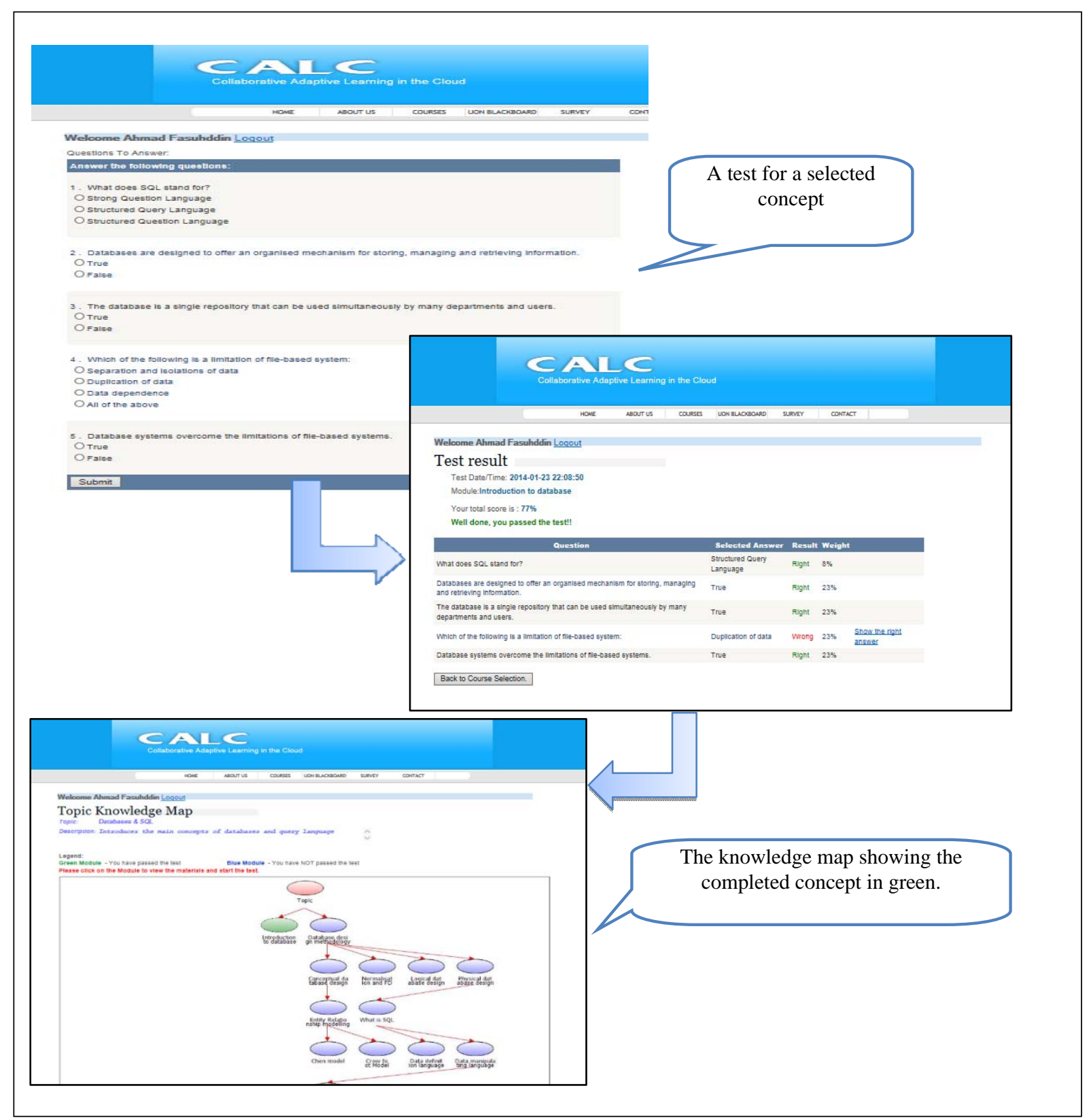

FIG. 3 SCREEN SHOTS OF TEST, REPORT AND THE UPDATED KNOWLEDGE MAP

For the pilot, an ongoing programming course was selected from the undergraduate IT program at the university. Prerequisite materials for that course were hosted on the CALC website and divided into three main topics to simulate the proposed model of CALC, taking the map shock limitation into consideration. Students enrolled in the course were invited to access the learning materials and use the knowledge maps. The students were invited to use CALC for a week before the commencement of the semester. This gave them the opportunity to learn and explore the learning materials independently which is one of the key factors of this study.

\section{Learning Materials Collection}

As mentioned earlier the selected course for this study was a programming course, and specifically it was web programming that taught ASP.net based on C\#. Prerequisite materials for the course were organised in three main topic, being ASP.net, $\mathrm{C \#}$ and databases, which lead to three knowledge maps. The learning materials were collected from different online open sources by lecturers and researchers at the university who have expertise in those fields to assure the quality and accuracy of these learning materials. Moreover, a variety of learners' learning styles, were considered in the material collection so materials in different formats (i.e. text, video, lecture slides) were collected and included in the knowledge maps in order to suit the preferences of different learners. According 
to Felder and Silverman (1988), learning styles refer to the way a learner receives and processes information.

\section{Self-Assessment Items}

The assessment items in the CALC website are multiple choice tests that allow learners to evaluate their learning for each concept. Sets of multiple choice questions were created for each concept by those who were involved in the learning material collection. The questions were weighted from 1 to 5 based on their importance and strength in relation to the concept, with 1 for the least strong to 5 for the most strong and important questions. This weight was designed in order to enhance the evaluation process so that better assessments could be achieved. Whenever a learner attempted a test for a concept, the test was generated with five randomly selected questions from the question bank for that concept. After the test was completed, the result was provided along with a detailed report that showed the weighted result of each question and whether it had been answered right or wrong. A screen shot of the test template and the result is presented in Fig. 3.

\section{Data Collection and Results}

The students who were invited to use the prototype and undertake the self-regulated learning experience using CALC were asked to provide their feedback through online Likert scale surveys. In addition, students were asked to provide their comments so as to collect qualitative data. The data collection was done in two stages: around the beginning of the semester and around the end of the semester. This was to compare whether students' perceptions differed before and after they had been taught by an instructor. The surveys were held to collect data and evaluate the learners' perceptions of the usage of knowledge maps and whether they help in conceptualising learning contents. Also, data about the incorporated features to CALC and students' perceptions of them in terms of how they impacted their learning process and overall support to learn independently were collected.

The two surveys were held at two different times of the semester. The first survey was around the third week of the semester and 24 responses were collected. The second survey was around the end of the semester and 25 responses were collected. The participating students were diverse with their ages ranging from 20 up to 35 . The surveys evaluated the perceived of usefulness by asking several questions for different aspects that lead to answer the posed research questions. Firstly, students were asked about the helpfulness in the use of knowledge maps to organise learning materials and conceptualise the learning contents. The survey questions for this aspect were: (a) the organisation of learning concepts in a knowledge map is helpful; (b) organising learning concepts in a knowledge map structure supports my learning and helps me to visualise the course contents; and (c) providing URL links in the knowledge map is a useful resource management feature. Students provided their perception through a 5 point Likert scale survey where $1=$ strongly disagree and $5=$ strongly agree. For each survey, the collected data for these three questions was accumulated to calculate the overall learners' perception about the usage of knowledge maps. The analysis for both surveys shows a skewed data distribution with median $=4.33$ and interquartile range $=1.33$ for survey 1 , and median $=4.33$ and interquartile range $=1.00$ for survey 2 . Fig. 4 presents these results. The result is promising and shows that most of the students agreed that the use of knowledge maps was beneficial in their learning process.

To compare between the result of the first and second survey and conclude whether the learners' perception about the knowledge maps had changed after they had been taught by an instructor, the Mann-Whitney non-parametric test was applied. The results showed that the difference was not statistically significant. Despite this result, both surveys show that most students found the knowledge maps to be supportive to their learning by helping in conceptualising learning contents.

In addition, the surveys had questions to collect data about the students' perception on the use of knowledge maps and how they support their independent learning. Two questions were used to elicit student perceptions in this regard: (a) the features in the knowledge maps model assisted me to learn independently; and (b) the organisation in knowledge maps helps me to learn independently. The responses of these two survey questions were accumulated and the overall learners' perception about the impact of knowledge maps on their independent learning was calculated for both surveys (i.e. survey 1 and survey 2). The analysis of both surveys showed a skewed data distribution which indicates that most of the students agreed that the knowledge maps supported them to learn independently. For the first survey the median $=4$ and the interquartile range $=1.50$. For the second 
survey the median $=4.50$ and the interquartile range $=1.25$. Fig. 5 shows these results.

By applying the Mann-Whitney statistical test, it was found that the difference between the students' perception in the first and second surveys was not statistically significant. However, it can be seen from the previous figure that the learners' perception about the knowledge maps and how they support their independent learning has slightly increased in the second survey as compared to the first survey.

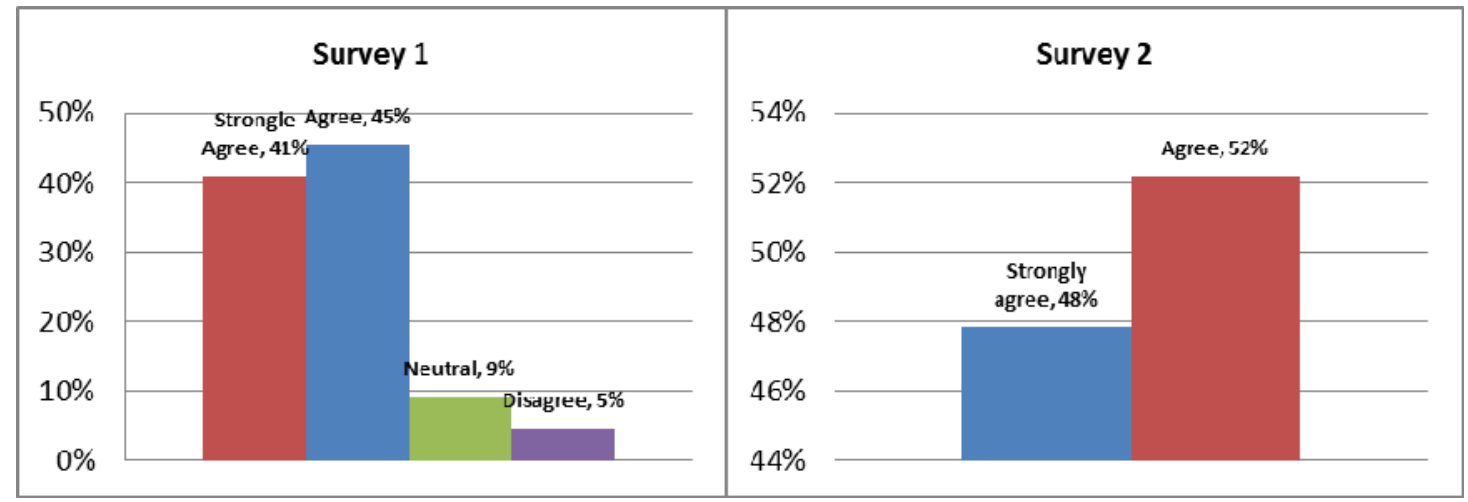

FIG. 3 STUDENTS' PERCEPTION ON THE USE OF KNOWLEDGE MAPS



FIG. 4 STUDENTS' PERCEPTION ON HOW KNOWLEDGE MAPS SUPPORT THEIR INDEPENDENT LEARNING

In addition to the previous questions, students were also surveyed about their satisfaction on the self- assessment items and whether they helped them to assess their learning progress and regulate their learning. Students were asked whether the provided self-assessments items were suitable for providing feedback on their learning needs. The results of both surveys show similar values for the median and the interquartile range on the 5 point Likert scale where $1=$ strongly disagree and $5=$ strongly agree. The resulting median $=4$ and interquartile range $=1$.

To evaluate the perceived ease-of use, students were asked whether the prototype was helpful and easy to use. For the first survey the median $=4$ and the interquartile range $=1.50$. For the second survey the median $=4$ and the interquartile range $=1$. The difference between the two survey results was not statistically significant. Furthermore, in the second survey students were asked whether they would like to use CALC in future learning and the resulting data shows a skewed distribution with median $=4$ and interquartile range $=1$. This is an indication that the incorporated features - the use of knowledge maps to organise learning contents along with the self-assessment items - were supportive for learners to learn in an open self-regulated learning environment.

In addition to the previously obtained data from the 5 point Likert scale questions, open ended questions were used to obtain qualitative feedback about the prototype implementation and pilot. The analysis of the qualitative data can be classified into two broad categories: (a) satisfactory responses and (b) feedback to improve the existing prototype. The satisfactory responses include highly positive feedback, such as: "The system is a fantastic idea and should be rolled out to other courses ...", "The system was interesting and engaging", "The CALC models were really helpful. $I^{\prime} d$ really like to use it again in future courses". The feedback on improvements included bug fixes and suggestions for improvements such as "... useful ones to provide a snippet of information with the answers explaining why they were correct. It could be a useful touch to this program". The reported bugs have been fixed and some of the suggestions were implemented. 
Overall, the obtained findings are promising and indicating that the proposed approach might be a supportive instrument for open learning environments.

\section{Limitations of the Study}

There are a number of factors that might limit the results of the presented study to be generalised. The study has been conducted on a programming course, which is technical in nature and learning materials can be captured in lectures, video, text and presented in an online form and concepts can be organised into a knowledge map. Different courses, especially courses that develop "soft skills" which may need interactive environments may not benefit as much from application of knowledge maps. In addition, the study has been conducted on a single offering with a small cohort. The results have more evidence if the study was repeated over multiple offerings. Furthermore, because this study has been piloted on a core content course at the university it was not permissible through ethics to include a control group. This is due to the fact that applying a control group requires some changes on the course teaching methods, and thus there are perceived inequalities for different student groups over the duration of the course. Notwithstanding the limitations, the median ratios of the findings were high and promising.

The authors plan to carry out another case study on this prototype with the addition of features, such as personalisation to enhance the learning experience.

\section{Conclusions}

This paper introduces a study that aims to increase the opportunities for open learning by applying learning theories and principles. The focus of this study has been to introduce an approach for organising and presenting learning materials to support self-regulated learning. Based on schema theory, knowledge maps (a graphical representation of learning concepts) were selected to organise and present learning materials. The main postulate of the study is that organising and presenting learning content using knowledge maps help in building a schema of learning concepts in learners' memories and consequently assist them in their learning process.

A prototype was developed as a website that simulates the open learning environment in terms of providing free materials that can be learnt at learners' pace. The prototype was piloted on a university course whereby prerequisite materials were collected and organised in knowledge maps. The students enrolled in the course were invited to use the prototype independently at their own pace, as is the case with the open learning environment. Students were invited to provide their perceptions about the use of knowledge maps and how they found these impacted on their learning process through surveys. A total of 49 student responses over two surveys were collected and analysed. Notwithstanding the limitations of the study, the results are promising and can be taken as an indication that knowledge maps are a suitable approach to support learners in open learning environments by helping them conceptualise learning contents and navigate their learning process.

\section{REFERENCES}

[1] Advancing Personalized Learning Via an Adaptive Concept Map. http://people.cs.vt.edu/ shaffer/CS6604/Papers/ASEE12.

[2] Amadieu, Frank, Tamara Van Gog, Fred Paas, Andre Tricot, and Claudette Mariné. 2009. "Effects of prior knowledge and concept-map structure on disorientation, cognitive load, and learning." Learning and Instruction no. 19 (5):376-386.

[3] Bartlett, Frederic. "Remembering: A study in experimental and social psychology." vol. 14: Cambridge University Press, 1995.

[4] Breslow, Lori B, David E. Pritchard, Jennifer DeBoer, Glenda S Stump, Andrew D Ho, and Daniel T Seaton. 2013. "Studying learning in the worldwide classroom: Research into edX's first MOOC." Research E Practice in Assessment no. 8:13-25.

[5] Briggs Geoffrey, David A Shamma, Alberto J Cañas, Roger Carff, Jeffrey Scargle, and JD Novak. 2004. Concept maps applied to Mars exploration public outreach. Paper read at The 1st international conference on concept mapping.

[6] Chalmers Patricia A. 2003. "The role of cognitive theory in human-computer interface." Computers in Human Behavior no. 
19 (5):593-607.

[7] Coffey JohnW. 2005. "LEO: A Concept Map Based Course Visualization Tool for Instructors and Students." In Knowledge and Information Visualization, edited by Sigmar-Olaf Tergan and Tanja Keller, 285-301. Springer Berlin Heidelberg.

[8] Coursera. 2012. Coursera 2012 [cited 25-7-2012]. Available from https://www.coursera.org/.

[9] Davis Fred D. 1989. "Perceived usefulness, perceived ease of use, and user acceptance of information technology." MIS quarterly:319-340. edX. 2012. edX 2012 [cited 26-5-2012]. Available from http://www.edxonline.org/.

[10] Fasihuddin, Heba, Geoff Skinner, and Rukshan Athauda. 2012. A Review of Contemporary Cloud Based E-learning Initiatives. In IADIS International Conference on Internet Technologies E Society. Perth, Australia.

[11] Hall, Richard H, Donald F Dansereau, and Lisa P Skaggs. 1992. "Knowledge maps and the presentation of related information domains." The Journal of Experimental Education no. 61 (1):5-18.

[12] Hall, Richard H, and Angela O'Donnell. 1996. "Cognitive and affective outcomes of learning from knowledge maps." Contemporary Educational Psychology no. 21 (1):94-101.

[13] Ifenthaler, Dirk, and Ria Hanewald. 2014. "Digital Knowledge Maps in Education." In Technology-Enhanced Support for Teachers and Learners: Springer New York.

[14] IHMC. 2013. IHMC Cmap Tool [cited 5/12/2013]. Available from http://cmap.ihmc.us/.

[15] Inspiration. 2014. Inspiration Software Incorporation 2014 [cited 22/1/2014 2014]. Available from http://www.inspiration.com/.

[16] KnowledgeMaster. 2014. Knowledge Master 2011 [cited 22/1/2014 2014]. Available from http://www.knowledgemanager.us/default-eng.htm.

[17] Li-Yu, Lee, Lin Yu-Shih, and Chu Chih-Ping. 2012. Constructing personal concept map automatically via Correlative TestItems Structure. In International Conference on Information Technology Based Higher Education and Training, 21-23 June 2012.

[18] MacKinnon, Gregory, Rohan Bailey, Patricia Livingston, VernonL Provencal, and Jon Saklofske. 2014. "Predispositions to Concept Mapping: Case Studies of Four Disciplines in Higher Education." In Digital Knowledge Maps in Education, edited by Dirk Ifenthaler and Ria Hanewald, 371-392. Springer New York.

[19] Moore, Jacob Preston, Robert Scott Pierce, and Christopher B Williams. 2012. Towards an" Adaptive Concept Map": Creating an Expert-Generated Concept Map of an Engineering Statics Curriculum. In American Society for Engineering Education.

[20] Ng, Wan, and Ria Hanewald. 2010. "Concept maps as a tool for promoting online collaborative learning in virtual teams with pre-service teachers." Handbook of research on collaborative learning using concept mapping:81-99.

[21] Novak, Joseph D, and Alberto J Cañas. 2006. "The theory underlying concept maps and how to construct them." Florida Institute for Human and Machine Cognition no. 1.

[22] Parr Chris. 2013. Mooc Creators Criticise Courses' Lack of Creativity [cited 5-11-2013]. Available from http://www.timeshighereducation.co.uk/news/mooc-creators-criticise-courses-lack-of-creativity/2008180.fullarticle

[23] Rewey, Kirsten L, Donald F Dansereau, Lisa P Skaggs, Richard H Hall, and Urvashi Pitre. 1989. "Effects of scripted cooperation and knowledge maps on the processing of technical material." Journal of Educational Psychology no. 81 (4):604.

[24] Safdar, Muhammad, Azhar Hussain, Iqbal Shah, and MH Tasnim. 2013. "Make the laboratory work meaningful through Concept maps and V Diagram." IOSR Journal of Research \& Method in Education no. 3:55-60.

[25] Satzinger, John W. 1998. "The effects of conceptual consistency on the end user's mental models of multiple applications." Journal of Organizational and End User Computing (JOEUC) no. 10 (3):3-15.

[26] Shaw, Ruey-Shiang. 2010. "A study of learning performance of e-learning materials design with knowledge maps." Computers \& Education no. 54 (1):253-264. doi: http://dx.doi.org/10.1016/j.compedu.2009.08.007.

[27] Sweller John. 1994. "Cognitive load theory, learning difficulty, and instructional design." Learning $\mathcal{E}$ instruction no. 4 
(4):295-312.

[28] Udacity. Meet Udacity! 2012. Available from http://www.udacity.com/.

[29] Udemy. 2014. Udemy 2014 [cited 22-1-2014]. Available from https://www.udemy.com/.

[30] Wang Minhong, Jun Peng, Bo Cheng, Hance Zhou, and Jie Liu. 2011. "Knowledge Visualization for Self-Regulated Learning." Educational Technology \& Society no. 14 (3):28-42.

[31] Williams, Joseph Jay. 2013. Improving learning in MOOCs with Cognitive Science. In AIED 2013 Workshops Proceedings Volume.

[32] Yuan, Li, and Stephen Powell. 2013. "MOOCs and Open Education: Implications for Higher Education." CETIS JISC no. 21:2013. 